\title{
A transgenic mouse model of human T cell leukemia virus type 1-associated diseases
}

\author{
Takeo Ohsugi* \\ Division of Microbiology and Genetics, Institute of Resource Development and Analysis, Kumamoto University, Kumamoto, Japan
}

\section{Edited by:}

Akio Adachi, The University of

Tokushima Graduate School, Japan

\section{Reviewed by:}

Yuetsu Tanaka, University of the

Ryukyus, Japan

Makoto Yamagishi, The University of

Tokyo, Japan

Seiji Okada, Kumamoto University,

Japan

\section{*Correspondence:}

Takeo Ohsugi, Division of

Microbiology and Genetics, Institute

of Resource Development and

Analysis, Kumamoto University, 2-2-1

Honjo, Kumamoto 860-0811, Japan.

e-mail: ohsugi@gpo.kumamoto-u.ac.jp
Human T cell leukemia virus type 1 (HTLV-1) is the etiological agent of adult $T$ cell leukemia/lymphoma (ATLL) and several inflammatory diseases. Tax, the protein encoded by HTLV-1, may be responsible for the development of the diseases caused by this virus. To investigate the pathogenic role of Tax, several transgenic mouse strains expressing Tax have been developed in recent years. These mice develop various tumors including large granular lymphocytic leukemia, as well as inflammatory diseases such as arthritis. These results suggest that Tax expression alone is sufficient to cause both malignant neoplastic diseases and inflammatory diseases. However, until recently, there were no tax transgenic mice that develop T cell leukemia and lymphoma resembling ATLL. The first successful induction of leukemia in T cells was pre-T cell leukemia generated in transgenic mice in which a mouse lymphocyte-specific protein tyrosine kinase p56/ck (/ck)-proximal promoter was used to express the tax gene in immatureT cells. Subsequently, transgenic mice were established in which the Ick-distal promoter was used to express Tax in mature T cells; these mice developed mature T cell leukemia and lymphoma that more closely resembled ATLL than did earlier mouse models.

Keywords: animal model, ATLL, HTLV-1, Tax, transgenic mice

\section{INTRODUCTION}

Human T cell leukemia virus type 1 (HTLV-1) was the first human retrovirus to be isolated (Poiesz et al., 1980). It is estimated that 10-20 million people worldwide are infected with HTLV-1, which is endemic in southwestern Japan, the Caribbean Islands, South America, and Africa. Infection with HTLV-1 can result in an aggressive malignancy known as adult $\mathrm{T}$ cell leukemia/lymphoma (ATLL) or in inflammatory diseases, such as HTLV-1-associated myelopathy/tropical spastic paraparesis (HAM/TSP), after a prolonged period of latency often lasting between 20 and 50 years (Watanabe, 1997). The lifetime incidence of ATLL among carriers of HTLV-1 was estimated to be $1-5 \%$, whereas that of HAM/TSP was $0.3-4.0 \%$ (Verdonck et al., 2007). The lifetime incidence of HTLV-1-associated diseases in general, including ATLL, HAM/TSP, and other inflammatory diseases, such as uveitis, polymyositis, arthropathy, and infective dermatitis, may be close to $10 \%$ (Verdonck et al., 2007). However, the reasons why HTLV1 -infected individuals develop different types of diseases and the mechanisms through which HTLV-1 causes these diseases remain unclear. To address these questions, an appropriate animal model is required.

\section{HTLV-1 GENOME}

The HTLV-1 genome consists of a diploid plus-strand RNA. Like other retroviruses, the integrated HTLV-1 proviral genome contains long-terminal-repeat (LTR) regions flanking the genes encoding the major structural proteins, gag, pol, and env. The genome also has an extra sequence designated $p X$. The $p X$ region has four partially overlapping open reading frames designated I, II, III, and IV, which encode the proteins p12, p13, and p30, Rex, and Tax, respectively (Grassmann et al., 2005; Matsuoka and Jeang,
2007). Tax and Rex act in combination to regulate HTLV-1 gene expression and replication in both positive and negative pathways (Yoshida, 2005). p12 is thought to facilitate persistent viral infection (Albrecht et al., 2000). p30 attenuates HTLV-1 transcription by suppressing Tax protein synthesis (Nicot et al., 2004). The role of p13 is currently unclear. The HTLV-1 minus-strand RNA encodes a basic leucine zipper factor (HBZ) and the protein is synthesized in an antisense fashion from the $3^{\prime}$ LTR (Larocca et al., 1989; Gaudray et al., 2002). HBZ inhibits Tax-mediated transactivation of viral transcription (Arnold et al., 2006; Lemasson et al., 2007; Clerc et al., 2008). However, several researchers have reported that HBZ mRNA, but not HBZ protein, could induce T cell proliferation and to promote cell survival (Satou et al., 2006; Arnold et al., 2008). At present, the role of HBZ in HTLV-1 infection is controversial. More recently, Satou et al. (2011) created $h b z$ transgenic mice and reported that more than one-third of these mice developed $\mathrm{T}$ cell lymphoma after a long latent period.

The transcription activator protein, Tax, is one of the regulatory proteins encoded by the $p X$ region that has been extensively studied in vitro. Tax is a $40 \mathrm{kDa}$ phosphoprotein that is essential for both viral replication and cellular transformation (Yoshida, 2001; Jeang et al., 2004). Transactivation of Tax is thought to initiate the processes that lead to ATLL or inflammatory diseases (Sun and Yamaoka, 2005; Matsuoka and Jeang, 2007; Currer et al., 2012; Yamagishi and Watanabe, 2012).

\section{tax TRANSGENIC MICE}

One of the best ways to investigate the oncogenic role(s) of tax in vivo is to generate a transgenic mouse model expressing HTLV-1 Tax (Table 1). The first HTLV-1 tax transgenic mice, in which Tax was expressed under the control of the HTLV-1 LTR, developed 
Table 1 | Representative tax transgenic mouse models.

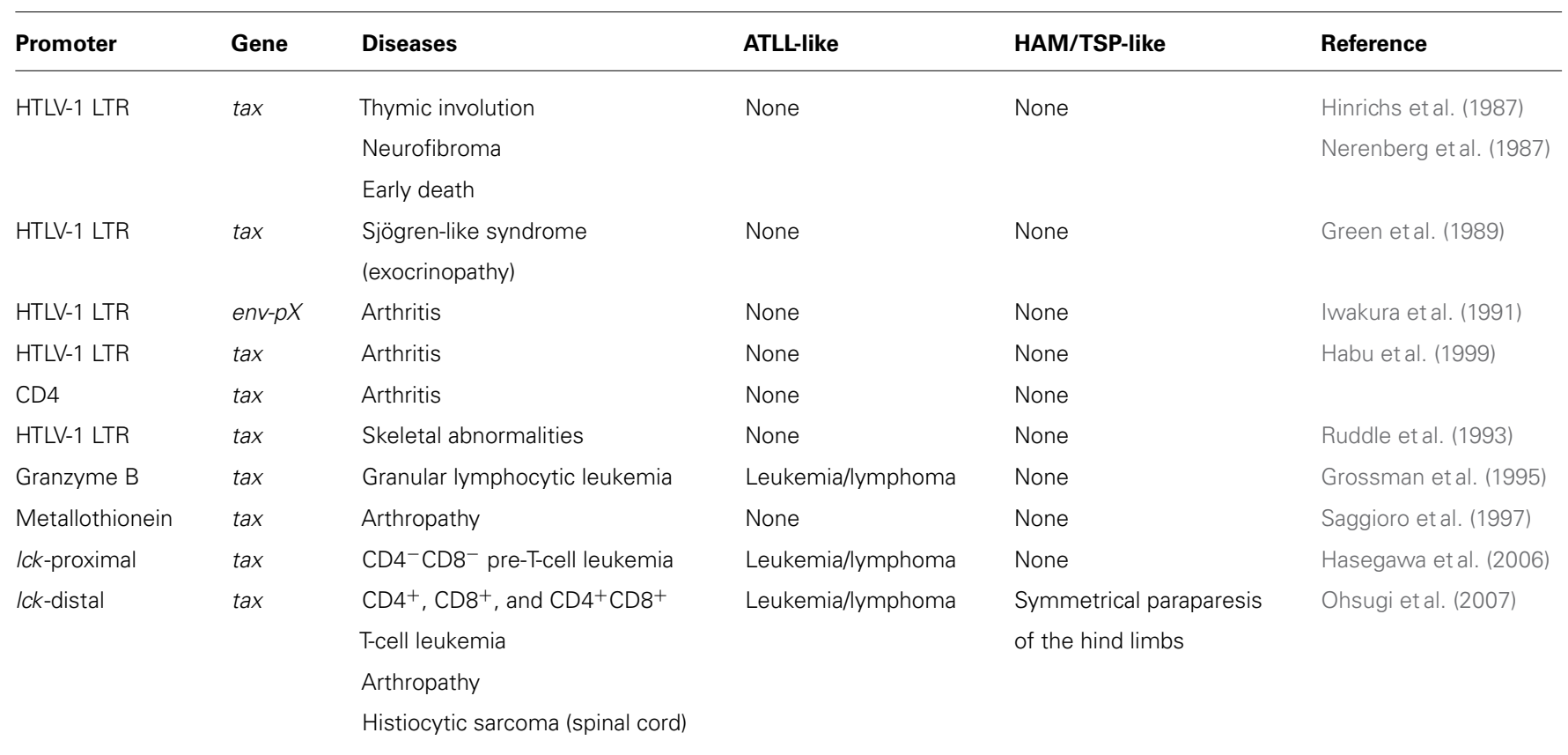

thymic involution, neurofibroma, and early death (Hinrichs et al., 1987; Nerenberg et al., 1987). Studies of these mice indicated that Tax expression alone was sufficient to induce tumorigenesis in transgenic mice. Iwakura et al. subsequently reported a very high incidence of inflammatory arthritis in transgenic mice carrying the HTLV-1 env- $p X$ region ( $p X$ transgenic mice) or tax with the HTLV-1 LTR promoter (Iwakura et al., 1991; Habu et al., 1999). Arthropathy develops in $p X$ transgenic mice as early as 4 weeks of age, and inflammatory arthropathy was also reported in another tax transgenic mouse model (Saggioro et al., 1997). These reports suggest that Tax expression induces inflammatory diseases in mice. Other transgenic mice were reported to develop Sjögren's-like syndrome (Green et al., 1989) and skeletal abnormalities (Ruddle et al., 1993).

However, none of these transgenic mouse models developed leukemia and lymphoma. The HTLV-1 LTR was used to regulate tax expression in these models. Other promoters were used in transgenic constructs to restrict tax expression to the lymphoid compartment and establish a better model of ATLL-like malignancies. Grossman et al. (1995) used the granzyme B promoter to drive tax expression in the mature $\mathrm{T}$ cell compartment. Those mice developed large granular lymphocytic leukemia, demonstrating that Tax expression alone in the lymphocyte compartment is sufficient for the development of leukemia.

\section{T CELL LEUKEMIA IN tax TRANSGENIC MICE}

Tax expression in transgenic mice caused large granular lymphocytic leukemia, but none of the transgenic mice developed T cell leukemia and lymphoma resembling ATLL. Recently, Hasegawa et al. (2006) established transgenic mice in which tax expression was restricted to thymocytes by using the lymphocyte-specific protein tyrosine kinase p56 ${ }^{l c k}(l c k)$-proximal promoter. These mice developed pre-T cell $\left(\mathrm{CD} 4^{-} \mathrm{CD} 8^{-} \mathrm{CD} 44^{+} \mathrm{CD} 25^{+}\right)$leukemia and lymphoma. Histological analysis showed diffuse, large-cell lymphomas involving the spleen, lymph nodes, liver, thymus, bone marrow, kidney, lung, meninges, and skin. The histopathological findings were identical to those observed in ATLL patients. The mice were functionally immunocompromised and developed opportunistic infections, which are also characteristics of ATLL. The leukemic cells were transplantable to severe combined immunodeficient mice. These transgenic mice demonstrated that Tax expression in the lymphocyte compartment is sufficient for the development of $\mathrm{T}$ cell leukemia and lymphoma. One major difference between these mice and humans with the disease is in the phenotype of the tumor cells, as the most common phenotype in ATLL in humans is CD4 ${ }^{+}$mature T cells (Watanabe et al., 1997; Matsuoka and Jeang, 2007; Verdonck et al., 2007).

We created a transgenic mouse model of HTLV-1 using the distal promoter of $l c k$ to express tax in mature T cells (Ohsugi et al., 2007). The expression of the $l c k$ gene is regulated by two distinct promoter elements, a proximal and a distal promoter (Voronova et al., 1987; Perlmutter et al., 1988; Takadera et al., 1989). The lck-proximal promoter is most active in immature thymocytes, whereas the activity of the distal promoter is higher in mature thymocytes and peripheral T lymphocytes (Reynolds et al., 1990; Wildin et al., 1991; Allen et al., 1992). Tax mRNA expression in various organs of the transgenic mice was examined by quantitative real-time RT-PCR. The thymus and spleen strongly expressed Tax mRNA. Over 2 years, $28.1 \%$ of the tax transgenic mice developed mature $\mathrm{T}$ cell leukemia/lymphoma compared with just $1 \%$ of non-transgenic littermates.

PHENOTYPE OF T CELL LEUKEMIA IN tax TRANSGENIC MICE The final cell specification to the $\mathrm{T}$ cell lineage takes place within the thymus. An overview of thymic T cell development is illustrated in Figure 1, and involves a series of distinct stages that 


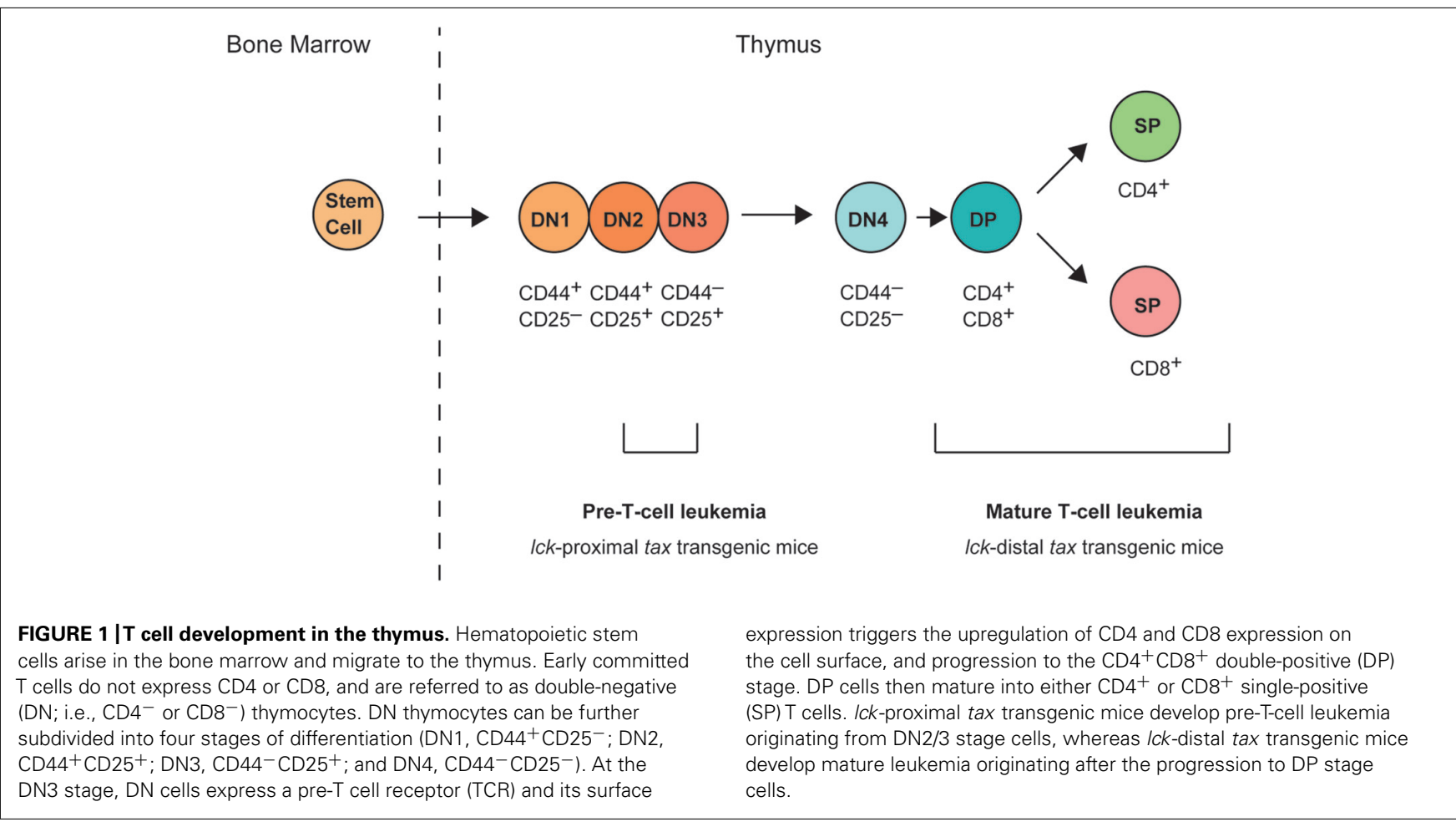

can be defined by the expression of cell-surface markers. Early T cells are $\mathrm{CD}^{-} \mathrm{CD}^{-}$double-negative (DN) and can be further subdivided into DN1 (CD44 $\left.{ }^{+} \mathrm{CD} 25^{-}\right)$, DN2 $\left(\mathrm{CD} 44^{+} \mathrm{CD} 25^{+}\right)$, $\mathrm{DN} 3\left(\mathrm{CD} 44^{-} \mathrm{CD} 25^{+}\right)$, and DN4 $\left(\mathrm{CD} 44^{-} \mathrm{CD} 25^{-}\right)$stages based on their expression of CD25 and CD44 (Koch and Radtke, 2011). The productive rearrangement of the $\mathrm{T}$ cell receptor (TCR) $\beta$ chain locus occurs during the DN3 to DN4 transition, and leads to the expression of the pre-TCR. Only cells expressing functional pre-TCR proliferate and differentiate into $\mathrm{CD} 4{ }^{+} \mathrm{CD} 8^{+}$ double-positive (DP) cells. However, most DP cells die through negative selection or neglect because their TCRs have too high or too low affinity for peptide-major histocompatibility complex molecule complexes. The cells that mature successfully migrate to the periphery as functional $\mathrm{CD} 4^{+} \mathrm{CD} 8^{-}$or $\mathrm{CD} 4^{-} \mathrm{CD} 8^{+}$ single-positive T cells.

The phenotype of $\mathrm{T}$ cell leukemia in lck-proximal tax transgenic mice was $\mathrm{CD} 4^{-} \mathrm{CD} 8^{-}$, but $\mathrm{CD} 44^{+}, \mathrm{CD} 25^{+}$, and $\mathrm{CD} 117^{-}$ (also known as c-kit ${ }^{-}$; Hasegawa et al., 2006). These results suggest that the malignant leukemic cells were derived from DN2/3 stage cells in the thymus. Transgenes controlled by the $l c k$-proximal promoter are expressed very early in T cell development and can be detected in DN1 cells, although their expression in the early progenitors is not homogeneous until the DN3/4 stage (Cleverley etal., 1999; Buckland etal., 2000). Various studies have suggested that the Lck tyrosine kinase plays an important role in thymocyte development as a signaling molecule downstream from pre-TCR (Mombaerts et al., 1994; Wallace et al., 1995; van Oers et al., 1996; Fehling etal., 1997), while pre-TCR was first detected in the CD44- CD25 ${ }^{+}$DN3 subset (Saint-Ruf et al., 1994; Bruno et al., 1995). A green fluorescent protein (GFP) transgenic mouse was created in which $g f p$ expression was under the control of the proximal promoter of $l c k$, and the earliest GFP-positive cells were found among the CD $44^{+} \mathrm{CD} 25^{-}$DN1 stage cells (Shimizu et al., 2001). Interestingly, pre-T cell leukemia in $l c k$-proximal tax transgenic mice was probably derived from DN2/3 stage cells, even though the $l c k$-proximal promoter is active in DN1-DN4 stage cells.

The phenotype of $\mathrm{T}$ cell leukemia in $l c k$-distal tax transgenic mice displayed $\mathrm{CD}^{+}{ }^{+}, \mathrm{CD}^{+}{ }^{+}$, or $\mathrm{CD}^{+}{ }^{+} \mathrm{CD} 8^{+}(\mathrm{DP}) \mathrm{T}$ cells. Overall, $60 \%$ of the leukemic cells were $\mathrm{CD}^{+} \mathrm{CD} 25^{-} \mathrm{T}$ cells, $25 \%$ were $\mathrm{CD} 4{ }^{+} \mathrm{CD} 25^{-} \mathrm{T}$ cells, and $15 \%$ were $\mathrm{CD} 4^{+} \mathrm{CD} 8^{+} \mathrm{T}$ cells (Ohsugi et al., 2007). As the Tax expression level did not vary in these cell populations, it remains unclear why $\mathrm{CD} 8^{+} \mathrm{T}$ cells comprised approximately $60 \%$ of the total mature T cell leukemia cells in the lck-distal tax transgenic mice.

\section{TAX-RELATED DISEASES IN tax TRANSGENIC MICE ARTHROPATHY}

tax transgenic mice develop an inflammatory arthropathy (Iwakura et al., 1991; Saggioro et al., 1997) that is pathologically similar to human rheumatoid arthritis and to mouse models of rheumatoid arthritis, with synovial proliferation and the expression of rheumatoid factor (Lee and Weinblatt, 2001; Luross and Williams, 2001; Firestein, 2003). By 24 months of age, our established $l c k$-distal tax transgenic mice without leukemia developed severe arthropathy, with a cumulative incidence of $22.8 \%$ (Ohsugi and Kumasaka, 2011), but no arthropathic mouse was reported among the $l c k$-proximal tax transgenic mice. The $l c k$-distal tax transgenic mice with arthropathy differ in several aspects from other transgenic mice. They develop arthropathy after a prolonged latency period of at least 9 months, whereas the arthropathy that develops in the $p X$ transgenic mice occurs as early as 4 weeks 
of age. At 3 months of age, 60\% (BALB/c background), $25 \%$ (C3H/He background), and $0 \%$ (C57BL/6 background) of $p X$ transgenic mice displayed arthropathy (Iwakura et al., 1998). The genetic background of our established lck-distal tax transgenic mice was the F1 generation of a BDF1 (DBA/2 $\times$ C57BL/6) cross with $\mathrm{C} 57 \mathrm{BL} / 6$. We attempted to generate lck-distal tax transgenic mice with the BALB/c background (backcross generation 8: N8), but did not observe a high incidence of arthropathy by 24 months of age. The expression of the cytokines interleukin$1 \beta$ (IL-1 $\beta$ ), IL-6, and macrophage migration inhibitory factor (MIF) was markedly enhanced in the joints of the lck-distal tax transgenic mice, but the expression of tumor necrosis factor- $\alpha$ (TNF- $\alpha$ ) was not elevated. Ashino et al. (2007) also found that serum IL-1 $\beta$ and IL- 6 concentrations were significantly higher in $p X$ transgenic mice than those in non-transgenic or nonarthritic $p X$ transgenic mice. Consistent with our arthropathic mice, their serum TNF- $\alpha$ concentrations were low, with no significant differences between the groups (Ashino et al., 2007). IL-6 is a key proinflammatory cytokine that is abundant in the synovium and synovial tissues of patients with rheumatoid arthritis (Okamoto et al., 1997). Taken together, these data suggest that proinflammatory cytokines, other than TNF- $\alpha$, are important in the development of the inflammatory arthropathy associated with Tax expression.

\section{HAM/TSP-LIKE DISEASE}

Eight out of 297 lck-distal tax transgenic mice developed HAM/TSP-like disease with symmetrical paraparesis of the hind limbs, whereas these symptoms were absent in their nontransgenic littermates and in other mouse strains at our animal facilities (Ohsugi et al., in press). The tax transgenic mice with HAM/TSP-like disease had spinal cord lesions in the lumbar vertebrae that were caused by the infiltration of bone marrowderived histiocytic sarcoma cells. Mice with HAM/TSP-like disease also displayed abnormal expression of cytokines and chemokines, including TNF- $\alpha$ and IL-6. Constitutive exposure to high levels of proinflammatory cytokines is thought to be protumorigenic (Balkwill, 2009; Grivennikov et al., 2009). Therefore, we speculated that tax-expressing $\mathrm{T}$ cells stimulate the proliferation of histiocytic cells in bone marrow through the activities of cytokines or chemokines. The transformed histiocytic cells may

\section{REFERENCES}

Albrecht, B., Collins, N. D., Burniston, M. T., Nisbet, J. W., Ratner, L., Green, P. L., et al. (2000). Human T-lymphotropic virus type 1 open reading frame $\mathrm{I} p 12^{\mathrm{I}}$ is required for efficient viral infectivity in primary lymphocytes. J. Virol. 74, 9828-9835.

Allen, J. M., Forbush, K. A., and Perlmutter, R. M. (1992). Functional dissection of the lck proximal promoter. Mol. Cell. Biol. 12, 2758-2768.

Arima, Y., Harada, M., Kamimura, D. Park, J. H., Kawano, F., Yull, F. E., et al. (2012). Regional neural activation defines a gateway for autoreactive $\mathrm{T}$ cells to cross the blood-brain barrier. Cell 148, 447-457.
Arnold, J., Yamamoto, B., Li, M., Phipps, A. J., Younis, I., Lairmore, M. D., et al. (2006). Enhancement of infectivity and persistence in vivo by HBZ, a natural antisense coded protein of HTLV-1. Blood 107, 39763982.

Arnold, J., Zimmerman, B., Li, M., Lairmore, M. D., and Green, P. L. (2008). Human T-cell leukemia virus type-1 antisense-encoded gene, $\mathrm{Hbz}$, promotes T-lymphocyte proliferation. Blood 112, 37883797.

Ashino, T., Arima, Y., Shioda, S., Iwakura, Y., Numazawa, S., and Yoshida, T. (2007). Effect of interleukin-6 neutralization on

then predominantly invade the lumbar spinal cord (Ohsugi et al., in press).

To my knowledge, there have been no reports of spontaneous symmetrical paraparesis caused by histiocytic sarcoma in mice. However, the lesions in patients with HAM/TSP show marked T cell infiltration, and the disease is associated with an inflammatory state (Sakai et al., 2001; Kubota et al., 2002; Goon et al., 2003; Muraro etal., 2003). Therefore, it is important to note that the etiology of HAM/TSP-like disease in lck-distal tax transgenic mice differs substantially from that of HAM/TSP in humans. Nevertheless, the present results indicate that the relationship between HTLV-1 infection and histiocytic disorders should be the focus of future studies. In particular, those studies should examine whether the cytokines and chemokines secreted from HTLV-1-infected T cells induce the growth or oncogenic transformation of histiocytic cells in humans. A recent paper proposed that, in a murine model of multiple sclerosis, there is a gateway through which immune cells can enter the central nervous system (Arima et al., 2012). The authors described an entry site by the dorsal blood vessels of the fifth lumbar cord through which immune cells can enter the central nervous system. Histiocytic sarcoma grew predominantly in the spinal cord of the fifth to sixth lumbar vertebrae in HAM/TSPlike mice. Further studies are required to confirm that histiocytic sarcoma cells can access the central nervous system via the spinal cord at the fifth lumbar vertebra. Such studies may clarify the mechanisms underlying the movement of Tax-positive T cells into the central nervous system in humans with HAM/TSP.

\section{CONCLUSION}

Several strains of HTLV-1 tax transgenic mice have been developed over recent years. Studies in these mice have shown that Tax expression alone is sufficient to cause both malignant neoplastic diseases, including $\mathrm{T}$ cell leukemia and lymphoma, and inflammatory diseases, such as arthropathy. These mice will be widely used to study the pathogenesis of HTLV-1 and to evaluate new anticancer and anti-inflammatory agents for HTLV-1-related diseases. However, until now, none of the tax transgenic mice developed HAM/TSP-like disease, a systemic immune-mediated inflammatory disease that resembles the disease in humans. Further studies are required to establish a transgenic mouse model of HAM/TSP with the selection of appropriate promoters.

CYP3A11 and metallothionein-1/2 expressions in arthritic mouse liver. Eur. J. Pharmacol. 558, 199-207.

Balkwill, F. (2009). Tumour necrosis factor and cancer. Nat. Rev. Cancer 9, 361-371.

Bruno, L., Rocha, B., Rolink, A., Von Boehmer, H., and Rodewald, $\mathrm{H}$. R. (1995). Intra- and extra-thymic expression of the pre-T cell receptor $\alpha$ gene. Eur. J. Immunol. 25, 1877-1882. Buckland, J., Pennington, D. J., Bruno, L., and Owen, M. J. (2000). Coordination of the expression of the protein tyrosine kinase $\mathrm{p} 56^{\text {lck }}$ with the pre-T cell receptor during thymocyte development. Eur. J. Immunol. 30, 8-18.
Clerc, I., Polakowski, N., Andre-Arpin, C., Cook, P., Barbeau, B., Mesnard, J. M., et al. (2008). An interaction between the human $\mathrm{T}$ cell leukemia virus type 1 basic leucine zipper factor (HBZ) and the KIX domain of p300/CBP contributes to the downregulation of tax-dependent viral transcription by HBZ. J. Biol. Chem. 283, 23903-23913.

Cleverley, S., Henning, S., and Cantrell, D. (1999). Inhibition of Rho at different stages of thymocyte development gives different perspectives on Rho function. Curr. Biol. 9, 657-660.

Currer, R., Van Duyne, R., Jaworski, E., Guendel, I., Sampey, G., Das, R., etal. (2012). HTLV Tax: 
a fascinating multifunctional coregulator of viral and cellular pathways. Front. Microbiol. 3:406. doi: 10.3389/fmicb.2012.00406

Fehling, H. J., Iritani, B. M., Krotkova, A., Forbush, K. A., Laplace, C., Perlmutter, R. M., et al. (1997). Restoration of thymopoiesis in $\mathrm{pT} \alpha^{-/-}$mice by anti-CD $3 \varepsilon$ antibody treatment or with transgenes encoding activated Lck or tailless pT alpha. Immunity 6 , 703-714.

Firestein, G. S. (2003). Evolving concepts of rheumatoid arthritis. Nature 423, 356-361.

Gaudray, G., Gachon, F., Basbous, J., Biard-Piechaczyk, M., Devaux, C., and Mesnard, J. M. (2002). The complementary strand of the human T-cell leukemia virus type 1 RNA genome encodes a bZIP transcription factor that down-regulates viral transcription. J. Virol. 76, 1281312822.

Goon, P. K., Igakura, T., Hanon, E., Mosley, A. J., Asquith, B., Gould, K. G., et al. (2003). High circulating frequencies of tumor necrosis factor alpha- and interleukin-2-secreting human T-lymphotropic virus type 1 (HTLV-1)-specific CD4 ${ }^{+} \mathrm{T}$ cells in patients with HTLV-1-associated neurological disease. J. Virol. 77, 9716-9722.

Grassmann, R., Aboud, M., and Jeang, K. T. (2005). Molecular mechanisms of cellular transformation by HTLV-1 Tax. Oncogene 24, 59765985.

Green, J. E., Hinrichs, S. H., Vogel, J., and Jay, G. (1989). Exocrinopathy resembling Sjogren's syndrome in HTLV-1 tax transgenic mice. Nature 341, 72-74.

Grivennikov, S., Karin, E., Terzic, J., Mucida, D., Yu, G. Y., Vallabhapurapu, S., et al. (2009). IL-6 and Stat3 are required for survival of intestinal epithelial cells and development of colitis-associated cancer. Cancer Cell 15, 103-113.

Grossman, W. J., Kimata, J. T., Wong, F. H., Zutter, M., Ley, T. J., and Ratner, L. (1995). Development of leukemia in mice transgenic for the tax gene of human T-cell leukemia virus type I. Proc. Natl. Acad. Sci. U.S.A. 92, 1057-1061.

Habu, K., Nakayama-Yamada, J., Asano, M., Saijo, S., Itagaki, K., Horai, R., etal. (1999). The human T cell leukemia virus type I-tax gene is responsible for the development of both inflammatory polyarthropathy resembling rheumatoid arthritis and noninflammatory ankylotic arthropathy in transgenic mice. J. Immunol. 162, 2956-2963.
Hasegawa, H., Sawa, H., Lewis, M. J., Orba, Y., Sheehy, N., Yamamoto, Y., et al. (2006). Thymus-derived leukemia-lymphoma in mice transgenic for the Tax gene of human Tlymphotropic virus type I. Nat. Med. 12, 466-472.

Hinrichs, S. H., Nerenberg, M., Reynolds, R. K., Khoury, G., and Jay, G. (1987). A transgenic mouse model for human neurofibromatosis. Science 237, 1340-1343.

Iwakura, Y., Itagaki, K., Ishitsuka, C., Yamasaki, Y., Matsuzawa, A., Yonehara, S., et al. (1998). The development of autoimmune inflammatory arthropathy in mice transgenic for the human $\mathrm{T}$ cell leukemia virus type1 env-pX region is not dependent on $\mathrm{H}-2$ haplotypes and modified by the expression levels of Fas antigen. J. Immunol. 161, 6592-6598.

Iwakura, Y., Tosu, M., Yoshida, E. Takiguchi, M., Sato, K., Kitajima, I., et al. (1991). Induction of inflammatory arthropathy resembling rheumatoid arthritis in mice transgenic for HTLV-I. Science 253, 1026-1028.

Jeang, K. T., Giam, C. Z., Majone, F., and Aboud, M. (2004). Life, death, and tax: role of HTLV-I oncoprotein in genetic instability and cellular transformation. J. Biol. Chem. 279, 31991-31994.

Koch, U., and Radtke, F. (2011). Mechanisms of $\mathrm{T}$ cell development and transformation. Annu. Rev. Cell Dev. Biol. 27, 539-562.

Kubota, R., Soldan, S. S., Martin, R., and Jacobson, S. (2002). Selected cytotoxic T lymphocytes with high specificity for HTLV-I in cerebrospinal fluid from a HAM/TSP patient. J. Neurovirol. 8, 53-57.

Larocca, D., Chao, L. A., Seto, M. H., and Brunck, T. K. (1989). Human T-cell leukemia virus minus strand transcription in infected T-cells. Biochem. Biophys. Res. Commun. 163, 10061013.

Lee, D. M., and Weinblatt, M. E. (2001). Rheumatoid arthritis. Lancet 358 903-911.

Lemasson, I., Lewis, M. R., Polakowski, N., Hivin, P., Cavanagh, M. H., Thebault, S., et al. (2007). Human T-cell leukemia virus type 1 (HTLV-1) bZIP protein interacts with the cellular transcription factor CREB to inhibit HTLV-1 transcription. J. Virol. 81, 1543-1553.

Luross, J. A., and Williams, N. A. (2001). The genetic and immunopathological processes underlying collageninduced arthritis. Immunology 103, 407-416.

Matsuoka, M., and Jeang, K. T. (2007). Human T-cell leukaemia virus type
1 (HTLV-1) infectivity and cellular transformation. Nat. Rev. Cancer 7, 270-280.

Mombaerts, P., Anderson, S. J., Perlmutter, R. M., Mak, T. W., and Tonegawa, S. (1994). An activated lck transgene promotes thymocyte development in RAG-1 mutant mice. Immunity 1 , 261-267.

Muraro, P. A., Wandinger, K. P., Bielekova, B., Gran, B., Marques, A., Utz, U., et al. (2003). Molecular tracking of antigen-specific $\mathrm{T}$ cell clones in neurological immunemediated disorders. Brain 126, 20-31.

Nerenberg, M., Hinrichs, S. H. Reynolds, R. K., Khoury, G., and Jay, G. (1987). The tat gene of human T-lymphotropic virus type 1 induces mesenchymal tumors in transgenic mice. Science 237, 1324 1329.

Nicot, C., Dundr, M., Johnson, J. M., Fullen, J. R., Alonzo, N., Fukumoto, R., et al. (2004). HTLV-1-encoded $\mathrm{p} 30^{\mathrm{II}}$ is a post-transcriptional negative regulator of viral replication. Nat Med. 10, 197-201.

Ohsugi, T., and Kumasaka, T. (2011). Low CD4/CD8 $\mathrm{T}$-cell ratio associated with inflammatory arthropathy in human T-cell leukemia virus type I Tax transgenic mice. PLoS ONE 6:e18518. doi: 10.1371/journal.pone. 0018518

Ohsugi, T., Kumasaka, T., Okada, S., and Urano, T. (2007). The Tax protein of HTLV-1 promotes oncogenesis in not only immature $T$ cells but also mature T cells. Nat. Med. 13, 527-528.

Ohsugi, T., Wakamiya, M., Morikawa, S., Matsuura, K., Kumar, J. M., Kumasaka, T., et al. (in press). Invasion of histiocytic sarcoma into the spinal cord of HTLV-1 Tax transgenic mice with HTLV-1associated myelopathy/tropical spastic paraparesis-like disease. Oncol. Res. (in press).

Okamoto, H., Yamamura, M., Morita, Y., Harada, S., Makino, H., and Ota, Z. (1997). The synovial expression and serum levels of interleukin-6, interleukin-11, leukemia inhibitory factor, and oncostatin $\mathrm{M}$ in rheumatoid arthritis. Arthritis Rheum. 40, 1096-1105.

Perlmutter, R. M., Marth, J. D., Lewis, D. B., Peet, R., Ziegler, S. F., and Wilson, C. B. (1988). Structure and expression of $l c k$ transcripts in human lymphoid cells. J. Cell. Biochem. 38, 117-126.

Poiesz, B. J., Ruscetti, F. W., Gazdar, A. F., Bunn, P. A., Minna, J. D., and Gallo, R. C. (1980). Detection and isolation of type C retrovirus particles from fresh and cultured lymphocytes of a patient with cutaneous T-cell lymphoma. Proc. Natl. Acad. Sci. U.S.A. 77, 7415-7419.

Reynolds, P. J., Lesley, J., Trotter, J., Schulte, R., Hyman, R., and Sefton, B. M. (1990). Changes in the relative abundance of type I and type II lck mRNA transcripts suggest differential promoter usage during T-cell development. Mol. Cell. Biol. 10, 4266-4270.

Ruddle, N. H., Li, C. B., Horne, W. C., Santiago, P., Troiano, N., Jay, G., et al. (1993). Mice transgenic for HTLV-I LTR-tax exhibit tax expression in bone, skeletal alterations, and high bone turnover. Virology 197, 196-204.

Saggioro, D., Rosato, A., Esposito, G., Rosenberg, M. P., Harrison, J., Felber, B. K., et al. (1997). Inflammatory polyarthropathy and bone remodeling in HTLV-I Taxtransgenic mice. J. Acquir. Immune Defic. Syndr. Hum. Retrovirol. 14, 272-280.

Saint-Ruf, C., Ungewiss, K., Groettrup, M., Bruno, L., Fehling, H. J., and Von Boehmer, H. (1994). Analysis and expression of a cloned pre-T cell receptor gene. Science 266, 1208-1212.

Sakai, J. A., Nagai, M., Brennan, M. B., Mora, C. A., and Jacobson, S. (2001). In vitro spontaneous lymphoproliferation in patients with human T-cell lymphotropic virus type I-associated neurologic disease: predominant expansion of $\mathrm{CD}^{+} \mathrm{T}$ cells. Blood 98, 15061511.

Satou, Y., Yasunaga, J., Yoshida, M., and Matsuoka, M. (2006). HTLV-I basic leucine zipper factor gene mRNA supports proliferation of adult $\mathrm{T}$ cell leukemia cells. Proc. Natl. Acad. Sci. U.S.A. 103, 720-725.

Satou, Y., Yasunaga, J., Zhao, T., Yoshida, M., Miyazato, P., Takai, K., et al. (2011). HTLV-1 bZIP factor induces T-cell lymphoma and systemic inflammation in vivo. PLoS Pathog. 7:e1001274. doi: 10.1371/journal.ppat.1001274

Shimizu, C., Kawamoto, H., Yamashita, M., Kimura, M., Kondou, E., Kaneko, Y., et al. (2001). Progression of $\mathrm{T}$ cell lineage restriction in the earliest subpopulation of murine adult thymus visualized by the expression of $l c k$ proximal promoter activity. Int. Immunol. 13, 105-117.

Sun, S. C., and Yamaoka, S. (2005). Activation of NF- $\kappa$ B by HTLV-I and implications for cell transformation. Oncogene 24, 5952-5964. 
Takadera, T., Leung, S., Gernone, A., Koga, Y., Takihara, Y., Miyamoto, N. G., et al. (1989). Structure of the two promoters of the human $l c k$ gene: differential accumulation of two classes of $l$ ck transcripts in T cells. Mol. Cell. Biol. 9, 2173-2180.

van Oers, N. S., Lowin-Kropf, B., Finlay, D., Connolly, K., and Weiss, A. (1996). $\alpha \beta \mathrm{T}$ cell development is abolished in mice lacking both Lck and Fyn protein tyrosine kinases. Immunity 5, 429-436.

Verdonck, K., Gonzalez, E., Van Dooren, S., Vandamme, A. M., Vanham, G., and Gotuzzo, E. (2007). Human T-lymphotropic virus 1: recent knowledge about an ancient infection. Lancet Infect. Dis. 7, 266-281.

Voronova, A. F., Adler, H. T., and Sefton, B. M. (1987). Two $l c k$ transcripts containing different $5^{\prime}$ untranslated regions are present in $\mathrm{T}$ cells. $\mathrm{Mol}$. Cell. Biol. 7, 4407-4413.

Wallace, V. A., Kawai, K., Levelt, C. N., Kishihara, K., Molina, T., Timms, E., et al. (1995). T lymphocyte development in $\mathrm{p} 56^{\text {lck }}$ deficient mice: allelic exclusion of the $\operatorname{TcR} \beta$ locus is incomplete but thymocyte development is not restored by $\operatorname{TcR} \beta$ or TcR $\alpha \beta$ transgenes. Eur. J. Immunol. 25, 1312 1318.

Watanabe, T. (1997). HTLV-1associated diseases. Int. J. Hematol. 66, 257-278.

Watanabe, T., Mochizuki, M., and Yamaguchi, K. (1997). HTLV-1 uveitis (HU). Leukemia 11(Suppl. 3), 582-584.

Wildin, R. S., Garvin, A. M., Pawar, S., Lewis, D. B., Abraham, K. M., Forbush, K. A., et al. (1991). Developmental regulation of lck gene expression in T lymphocytes. J. Exp. Med. 173, 383-393.

Yamagishi, M., and Watanabe, T. (2012). Molecular hallmarks of adult $\mathrm{T}$ cell leukemia. Front. Microbiol. 3:334. doi: 10.3389/fmicb.2012.00334

Yoshida, M. (2001). Multiple viral strategies of HTLV-1 for dysregulation of cell growth control. Annu. Rev. Immunol. 19, 475-496.

Yoshida, M. (2005). Discovery of HTLV1 , the first human retrovirus, its unique regulatory mechanisms, and insights into pathogenesis. Oncogene 24, 5931-5937.

Conflict of Interest Statement: The author declares that the research was conducted in the absence of any commercial or financial relationships that could be construed as a potential conflict of interest.

Received: 29 January 2013; accepted: 21 February 2013; published online: 08 March 2013.

Citation: Ohsugi T (2013) A transgenic mouse model of human $T$ cell leukemia virus type 1-associated diseases. Front. Microbiol. 4:49. doi: 10.3389/fmicb.2013.00049

This article was submitted to Frontiers in Virology, a specialty of Frontiers in Microbiology.

Copyright (c) 2013 Ohsugi. This is an open-access article distributed under the terms of the Creative Commons Attribution License, which permits use, distribution and reproduction in other forums, provided the original authors and source are credited and subject to any copyright notices concerning any thirdparty graphics etc. 